\title{
Research on the Influence of Brand Certification on Farmers' Professional Cooperatives Participating in E-commerce
}

\author{
Guoqiang Liu ${ }^{1, \mathrm{a}}$, Bizhong Zhang ${ }^{1, \mathrm{~b}}$, Xinhong $\mathrm{Fu}^{* 1, \mathrm{c}}$, Ruixin Zhang ${ }^{1, \mathrm{~d}}$ \\ ${ }^{1}$ College of Management, Sichuan Agricultural University, Chengdu, China
}

\begin{abstract}
Based on the microscopic survey data of 100 vegetable cooperatives in Sichuan Province, this paper empirically analyzes the influence of brand certification on cooperatives participating in the ecommerce by binary logistic regression model. The results show that the proportion of Sichuan vegetable cooperatives participating in the e-commerce is generally lower, which needs further improvement. Brand certification has a positive role in promoting cooperatives to participate in the e-commerce, with a marginal contribution of $19.7 \%$. In addition, government sales support has a positive impact on the cooperative ecommerce, which is an important guarantee for promoting cooperatives to participate in the e-commerce. While the difficulty of agricultural product sales has a negative impact on the cooperative e-commerce, and the more difficult the agricultural products are sold, the higher the probability that the cooperative will participate in the e-commerce. Thus, this article puts forward policy suggestions such as actively promoting cooperatives to participate in brand certification, promoting cooperatives to participate in the e-commerce according to local conditions and strengthening government sales support.
\end{abstract}

\section{Introduction}

Farmers' professional cooperatives (hereinafter referred to as "cooperatives") have important functions such as reducing transaction costs and resolving information asymmetry ${ }^{[1,2]}$, which can effectively resolve the problems of agricultural products' sales, and thus have developed rapidly. According to the official data from the Ministry of Agriculture and Rural Affairs, the number of legally registered cooperatives nationwide amounted to 2.203 million as of the end of October 2019, and about half of the rural households entered the cooperatives. Cooperatives have become one of the most important new type of agricultural management entities for the development of modern agriculture. However, it is undeniable that the cooperative has not fundamentally solved the problem of agricultural products' sales ${ }^{[3]}$, so the sustainable development of the cooperatives also face challenges. Higher transaction costs are an important factor that makes it difficult to sell agricultural products ${ }^{[4]}$. The transaction costs of cooperatives mainly come from various transaction activities carried out between cooperatives and other market entities. Cooperatives participating in e-commerce can effectively reduce search costs, negotiation and decision costs, supervision costs, switching costs, etc ${ }^{[5]}$. In addition, the development of ecommerce can enhance the market competitiveness of cooperatives, improve the level of standardized management and the quality of members ${ }^{[6]}$. Therefore, Kong pointed out that not only e-commerce needs cooperatives, but cooperatives also need e-commerce ${ }^{[7]}$.
The government strongly supports cooperatives to develop e-commerce. In order to actively respond to the "Internet +" action, the 2017 Central Document No. 1 emphasized the promotion of comprehensive docking and integration between cooperatives and e-commerce. However, with the policies promotion in the past five years, there is a certain gap between the cooperatives' ecommerce practice and theoretical expectations. There are still some cooperatives that have not participated in ecommerce. Why do cooperatives have a different attitude towards e-commerce, that is, what factors affect the cooperatives participating in e-commerce? Answering this question has important theoretical and practical significance for resolving the sales difficulties of agricultural products and the sustainable development of cooperatives.

\section{LITERATURE REVIEW}

The model and advantages of cooperatives participating in e-commerce have attracted extensive attention from scholars. "Production and sales docking" and "production and consumption docking" are two basic circulation paths of cooperatives' agricultural products, from which the ecommerce is an important form of the former ${ }^{[8]}$. The model of cooperatives participating in e-commerce mainly includes $\mathrm{C} 2 \mathrm{O}$ model, $\mathrm{COM}$ model and $\mathrm{CO} 2 \mathrm{O}$ model ${ }^{[9]}$. Similarly, Chen et al. found that the supply and demand information release model, the self-operated outlet model and the entrusted sales model are cooperatives' common e-commerce model ${ }^{[10]}$. Xu and Si explored feasible e- 
commerce models for several main types of agricultural products, namely, food crop agricultural products adopting the information platform model and the supply and marketing integration model driven by leading enterprises, fresh agricultural products using small community e-commerce and the online store model, the specialty agricultural products adopting the third-party platform model and the self-operated platform model, the economic forest products adopting the agricultural product auction model and the large-scale procurement model ${ }^{[11]}$. The advantages of cooperatives in developing ecommerce are mainly in two aspects, namely, the high degree of organization and the latecomer advantage ${ }^{[12]}$. Compared with traditional sales in the bazaar, cooperatives participating in e-commerce face a larger market and stronger premium capacity ${ }^{[13]}$, Yang and Wang pointed out that cooperatives can reduce transaction costs such as search costs, negotiation and decision-making costs, supervision costs and conversion costs ${ }^{[5]}$, thereby promoting the sales of agricultural products and the sustainable development of cooperatives.

However, the practice of cooperatives participating in e-commerce is affected by many factors. $\mathrm{Wu}$ and Qiu pointed out that when operating fresh e-commerce platform, the cooperatives lack the management consciousness to manage the enterprise with a modern enterprise system, the concepts of Internet integrated marketing, and the logistics are imperfect, besides, a gap in the standard system of agricultural products circulation $^{[14]}$. Cooperatives participating in e-commerce face many bottlenecks such as lack of talents, little influence of agricultural products' brands, inadequate logistics system, insufficient consumer information and inadequate policy implementation ${ }^{[9]}$. Public policy is an important driver of rural e-commerce development ${ }^{[15]}$. Kong pointed out that the chairman of the cooperative needs to have strategic thinking and take participation in e-commerce as a long-term and strategic task ${ }^{[7]}$. Cooperatives' e-commerce cognitive behavior is not affected by the scale of operations, but it is significantly affected by the type of industry ${ }^{[15]}$. Zhang found that farmers joining the cooperatives will reduce the willingness of small farmers to participate in the ecommerce $^{[16]}$. Factors such as interpersonal trust, institutional trust, gender, education, family cultivated area, family annual income, proportion of labor and whether there is a village-level information service station in the village have a significant impact on cooperatives' decision-making in participating in the e-commerce operations $^{[17]}$. Among the influencing factors of farmers' ecommerce cooperative entrepreneurial behavior, farmers' age, family labor and trust with relatives or friends have the greatest impact on farmers' e-commerce cooperative entrepreneurial behavior, Social ability and other factors followed ${ }^{[18]}$. The influence of human resources factors on the cooperatives' willingness to participate in e-commerce is more significant. Measures such as increasing capital investment in cooperative development, organizing cooperatives to operate on a moderate scale, improving the technical level of cooperative members and establishing cooperative development experience exchange platforms can all help develop cooperative e-commerce ${ }^{[19]}$. Liu et al. found that the chairman's education level, production base, cooperative registration capital, agricultural product sales channels, whether to sign purchase and sales contracts, etc have a positive correlation with e-commerce behavior, while whether the cooperative has a fixed education and training place and incomplete member product transaction records have a negative correlation ${ }^{[20]}$.

The influence of brand certification on marketing has also gradually attracted the attention of scholars. Dorr found that certified mangoes and grapes increased by $58 \%$ and $28 \%$ per kilogram over uncertified prices ${ }^{[21]}$, respectively. Brands had a significant positive effect on the online sales price, sales volume and satisfaction of fruits, and the interaction effect between brand and culture had a significant positive effect on the online sales price of tea ${ }^{[22]}$, while some scholars hold the opposite view, Bacon pointed out that fair trade and organic certification did not improve the livelihoods of 228 small coffee farmers in northern Nicaragua ${ }^{[23]}$. Jena et al. believed that due to low productivity, negligible price premiums and poor access for cooperatives to credit and information, coffee cooperatives' certification had little impact on the livelihoods of small-scale coffee producers ${ }^{[24]}$. Owning your own brand was a necessary software condition for the cooperative e-commerce ${ }^{[25]}$. With the rapid development of e-commerce applications in China, cooperatives developed e-commerce and took the brand path to meet the needs of market competition ${ }^{[26]}$.

In summary, scholars have conducted extensive discussions on the models and advantages of the cooperative e-commerce, the influencing factors of cooperatives participating in e-commerce, and the impact of brand certification, which have laid the foundation for in-depth research in this article. However, it is slightly inadequate. Existed researches mostly have theoretical discussions on cooperatives' e-commerce models or advantages, but lack of empirical research on the influencing factors of cooperatives participating in the ecommerce. There have been studies examining the influencing factors of cooperatives participating in ecommerce from the dimensions of the chairman's characteristic variables, cooperative characteristic variables and environmental characteristic variables. Moreover, some scholars concern about the influence of brand certification on marketing, however, lacking the attention to the influence of brand certification on cooperatives participating in the e-commerce, a new marketing method. Further speaking, how much is the impact? Which needs to be further investigated. At the same time, the industry types of cooperatives in the existed research are diverse, and the cooperatives with different types of industries have large differences in e-commerce behaviors. Thus, it is necessary to reduce the influence of industrial heterogeneity on cooperatives participating in the e-commerce. Therefore, based on the microscopic survey data of 100 vegetable cooperatives in Sichuan Province, this article uses the binary logistic regression model to empirically analyze the influence of brand certification on cooperatives participating in the ecommerce and calculates the marginal effects, which has a certain degree of innovation. 


\section{Data sources}

This article takes vegetable Cooperatives in Sichuan province as an example to deeply analyze the influence of brand certification on cooperatives participating in the ecommerce. Sichuan is divided into five economic zones according to economic and geographic features, that is, Chengdu Plain Economic Zone, Southern Sichuan Economic Zone, Northeastern Sichuan Economic Zone, Panxi Economic Zone and Northwest Sichuan Ecological Economic Zone. Because the development level of cooperatives in Panxi Economic Zone and Northwest Sichuan Ecological Economic Zone is generally lower, and at the same time limited by the time and energy, this article focus on Chengdu Plain Economic Zone, Southern Sichuan Economic Zone and Northeast Sichuan Economic Zone, which can basically represent the development profile of most cooperatives in Sichuan Province. Therefore, this research conducted a questionnaire survey from July 15 to 26, 2019. The survey mainly used stratified random sampling: Firstly, randomly select 2 or 3 cities in each economic zone; Secondly, randomly select 2 or 3 counties (cities or districts) with large output of vegetables in each sample city; Thirdly, randomly select 4-8 vegetable cooperatives in each sample counties (cities or districts), and then conduct surveys on their directors or board members; Finally, a total of 110 questionnaires were distributed in the survey, and 105 questionnaires were recovered, with a recovery rate of $95.45 \% .100$ valid questionnaires were collected after invalid questionnaires with incomplete information and wrong logic were excluded, and the effective rate is $95.24 \%$. The regional distribution of valid samples of cooperatives is shown in table 1 .

Table1. Regional distribution of valid samples

\begin{tabular}{|c|c|c|c|c|}
\hline $\begin{array}{c}\begin{array}{c}\text { Economic } \\
\text { Zone }\end{array} \\
\end{array}$ & $\begin{array}{c}\text { Sample } \\
\text { City }\end{array}$ & $\begin{array}{c}\text { Sample counties } \\
\text { (cities or districts) }\end{array}$ & \begin{tabular}{|c|} 
Valid \\
Samples
\end{tabular} & Proportion(\%) \\
\hline \multirow{4}{*}{$\begin{array}{l}\text { Southern } \\
\text { Sichuan } \\
\text { Economic } \\
\text { Zone }\end{array}$} & \multirow{2}{*}{ Neijiang } & Zizhong County & 5 & 5.00 \\
\hline & & Dongxing District & 4 & 4.00 \\
\hline & \multirow{2}{*}{ Luzhou } & Lu County & 6 & 6.00 \\
\hline & & Hejiang County & 6 & 6.00 \\
\hline \multirow{7}{*}{$\begin{array}{l}\text { Northeast } \\
\text { Sichuan } \\
\text { Economic } \\
\text { Zone }\end{array}$} & \multirow{2}{*}{ Nanchong } & Shunqing District & 5 & 5.00 \\
\hline & & Gaoping District & 6 & 6.00 \\
\hline & \multirow{2}{*}{ Guang'an } & Yuechi County & 6 & 6.00 \\
\hline & & Wusheng County & 6 & 6.00 \\
\hline & \multirow{3}{*}{ Guangyuan } & Lizhou District & 5 & 5.00 \\
\hline & & Zhaohua District & 5 & 5.00 \\
\hline & & Cangxi County & 5 & 5.00 \\
\hline \multirow{7}{*}{$\begin{array}{l}\text { Chengdu } \\
\text { Plain } \\
\text { Economic } \\
\text { Zone }\end{array}$} & \multirow{3}{*}{ Chengdu } & Pidu District & 6 & 6.00 \\
\hline & & Pengzhou city & 6 & 6.00 \\
\hline & & Jintang County & 7 & 7.00 \\
\hline & \multirow{2}{*}{ Deyang } & Jingyang District & 4 & 4.00 \\
\hline & & Zhongjiang county & 5 & 5.00 \\
\hline & \multirow{2}{*}{ Meishan } & Dongpo District & 7 & 7.00 \\
\hline & & Renshou County & 6 & 6.00 \\
\hline Total & 8 & 18 & 100 & 100.00 \\
\hline
\end{tabular}

\section{Model setting and variable selection}

\subsection{Model setting}

The dependent variable in this article is the cooperative ecommerce, whose value includes participating in the ecommerce and non-participating in the e-commerce. Cooperative e-commerce is a typical binary discrete variable. The binary logistic regression model is an effective method to estimate the binary discrete variable. Therefore, this article analyze the influence of brand certification on the cooperative e-commerce by binary logistic regression model. The basic form of the binary logistic regression model is:

$$
P_{i}=F\left(\alpha+\sum_{j=1}^{n} \beta_{j} x_{j}\right)=\frac{1}{1+e^{-\left(\alpha+\sum_{j=1}^{n} \beta_{j} x_{j}\right)}}
$$

In the above formula, $P_{i}(i=1,2, \ldots \ldots, 100)$ represents the probability of the cooperative to participate in ecommerce; $\alpha$ is a constant term; $n(n=7)$ is the number of independent variables, including core independent variables and control variables; $\beta_{j}$ is the regression coefficient of $x_{j}$, and $x_{j}$ is the independent variable. Logarithmically transform the above formula to obtain a linear expression of the logistic regression model:

$$
\ln \left(\frac{P_{i}}{1-P_{i}}\right)=\alpha+\sum_{j=1}^{n} \beta_{j} x_{j}
$$

\subsection{Variable selection}

The dependent variable in this article is the cooperative ecommerce, which specifically refers to whether the cooperatives participate in the e-commerce. The value of the cooperative e-commerce has two states, namely, participating in the e-commerce and non-participating in the e-commerce. The survey data shows that there are 46 sample cooperatives participating in the e-commerce, accounting for $46 \%$, while 54 sample cooperatives not participating in the e-commerce, accounting for $54 \%$. Therefore, the level of e-commerce development in cooperatives is generally lower, which needs further development.

The core independent variable of this article is brand certification, which specifically refers to whether the cooperative has a brand, for example, "Three products and one standard", own brand, etc. The value of brand certification also has two states, namely, having brand certification and no brand certification. According to the survey data, there are 76 sample cooperatives with brand certification, accounting for $76 \%$. While 24 sample cooperatives without brand certification, accounting for $24 \%$.

In addition, based on the previous theoretical analysis, the chairman's characteristic variables, other cooperative characteristic variables and environmental characteristic variables may have a certain influence on the cooperative e-commerce. Therefore, in order to further investigate the influence of brand certification on the cooperative ecommerce, variables such as the special experience of the chairman of the board, the time length of the cooperative's establishment, the voting methods of the three associations, the profitability of the cooperative compared 
with the previous two years, the difficulty of agricultural product sales, the government sales support are set as control variables. The descriptive statistics of each variable is shown in table 2 .

Table2. Definition and description of variables

\begin{tabular}{|c|c|c|c|}
\hline Variable name & Variable Defination & Mean & SE \\
\hline \multicolumn{4}{|l|}{ Dependent variable } \\
\hline $\begin{array}{l}\text { Cooperative e-commerce } \\
(y)\end{array}$ & $\begin{array}{l}0=\text { participating in; } \\
1=\text { non-participating in }\end{array}$ & 0.46 & 0.50 \\
\hline \multicolumn{4}{|l|}{ Core independent variable } \\
\hline Brand certification $\left(x_{1}\right)$ & $0=$ no; $1=$ yes & 0.76 & 0.43 \\
\hline \multicolumn{4}{|l|}{ control variables } \\
\hline $\begin{array}{l}\text { the special experience of the } \\
\text { chairman }\left(x_{2}\right)\end{array}$ & $\begin{array}{l}0=\text { no; } 1=\text { Village cadres } \\
\text { or party members }\end{array}$ & 0.62 & 0.49 \\
\hline $\begin{array}{l}\text { the time length of the } \\
\text { cooperative's establishment } \\
\left(x_{3}\right)\end{array}$ & Actual value (year) & 7.50 & 3.14 \\
\hline $\begin{array}{l}\text { the voting methods of the } \\
\text { three associations }\left(x_{4}\right)\end{array}$ & $\begin{array}{l}0=\text { other; } 1=\text { "One } \\
\text { person, one vote" }\end{array}$ & 0.74 & 0.44 \\
\hline $\begin{array}{l}\text { the profitability of the } \\
\text { cooperatives compared with } \\
\text { the previous two years }\left(x_{5}\right)\end{array}$ & $\begin{array}{l}1=\text { a lot worse; } 2=\mathrm{a} \\
\text { little worse; } 3=\text { no } \\
\text { difference; } 4=\text { a little } \\
\text { better; } 5=\text { a lot better }\end{array}$ & 3.75 & 0.94 \\
\hline $\begin{array}{l}\text { the difficulty of agricultural } \\
\text { product sales }\left(x_{6}\right)\end{array}$ & $\begin{array}{l}1=\text { very difficult; } 2= \\
\text { difficult; } 3=\text { normal; } 4 \\
=\text { easy; } 5=\text { very easy }\end{array}$ & 4.12 & 0.83 \\
\hline $\begin{array}{l}\text { the government sales support } \\
\left(x_{7}\right)\end{array}$ & $0=$ no; $1=$ yes & 0.77 & 0.42 \\
\hline
\end{tabular}

\section{Empirical analysis results}

\subsection{Regression and marginal analysis results}

This article tests the multicollinearity among independent variables before binary logistic regression analysis. The results show that the variance expansion factor of each variable is less than 10 , indicating that there is no significant multicollinearity. Thus, this article uses stata14.0 statistical and analysis software to estimate the model. The regression results are shown in table 3 , from which the model $\mathrm{I}$ is the regression results based on the control variables, and model II based on all variables. The log-likelihood values of the two models are -63.131 and 61.696, while Pseudo R2 are 0.085 and 0.106 , and the probability values are 0.068 and 0.042 , respectively. Two models all pass the significance test at the $10 \%$ or $5 \%$ levels, indicating that the overall fit of the model is good. It should be particularly emphasized that the sign of the regression coefficient can reflect the influence direction of each variable, but its size has no direct significance. In order to further analyze the influence degree of each variable on the cooperative e-commerce, this article calculates the marginal effect of each variable, which is also shown in table3.

Table3. Regression and marginal results

\begin{tabular}{|c|c|c|c|c|}
\hline \multirow{3}{*}{ Variables } & \multicolumn{2}{|c|}{ Module I } & \multicolumn{2}{c|}{ Module II } \\
\cline { 2 - 5 } & $\begin{array}{c}\text { Regression } \\
\text { coefficient }\end{array}$ & $\begin{array}{c}\text { Marginal } \\
\text { coefficient }\end{array}$ & $\begin{array}{c}\text { Regression } \\
\text { coefficient }\end{array}$ & $\begin{array}{c}\text { Marginal } \\
\text { coefficient }\end{array}$ \\
\hline$x_{1}$ & - & - & $0.922^{*}$ & $0.197^{*}$ \\
\hline$x_{2}$ & 0.164 & 0.036 & 0.222 & 0.047 \\
\hline$x_{3}$ & 0.076 & 0.017 & 0.056 & 0.012 \\
\hline$x_{4}$ & -0.102 & -0.023 & -0.027 & -0.005 \\
\hline$x_{5}$ & 0.16 & 0.035 & 0.106 & 0.022 \\
\hline$x_{6}$ & $-0.622^{* *}$ & $-0.138^{* *}$ & $-0.547^{*}$ & $-0.117^{* *}$ \\
\hline
\end{tabular}

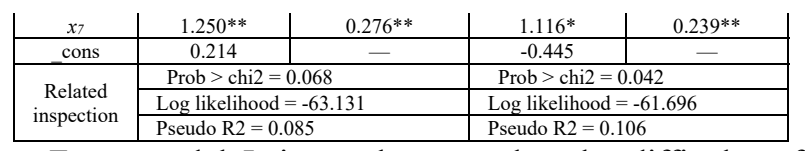

From model I, it can be seen that the difficulty of agricultural product sales passes the significance test at the $5 \%$ level, and the influence direction is negative, showing that the more difficult it is to sell agricultural products, the higher the probability of cooperatives participating in the e-commerce. The marginal coefficient is -0.138 , which further indicates that the probability of cooperatives participating in the e-commerce increases by an average of $13.8 \%$ with the difficulty of agricultural product sales down one level. Therefore, cooperatives can innovate marketing by e-commerce where agricultural products are difficult to sell. Cooperatives open sales channels for agricultural products through the sales combination between online and offline, which also promotes their own sustainable development. Government sales support passes the 5\% level of significance test, and the influence direction is positive, indicating that the cooperatives that receive government sales support have a higher probability participating in the e-commerce. The marginal coefficient is 0.276 , which shows that the probability of participating in the e-commerce for cooperatives with government sales support has increased by an average of $27.6 \%$ compared with those not. Thus, government's sales support has a positive role in promoting the cooperative ecommerce. In addition, other variables such as the special experience of the chairman, the time length of the cooperative's establishment, the voting methods of the three associations, the profitability of the cooperatives compared with the previous two years fail the significance test at the $10 \%$ level, showing that whether the chairman has special experience, how long the cooperative was established, the standardization level and the profitability of the cooperative have no significant influence on the cooperative e-commerce.

From model II, it can be seen that brand certification, the core independent variable, passes the $10 \%$ level of significance test, and the influence direction is positive, indicating that the cooperative with brand certification has a higher probability of participating in the e-commerce. The marginal coefficient is 0.197 , indicating that the cooperative with brand certification have an average increase of $19.7 \%$ in the probability of participating in the e-commerce. Thus, brand certification is an effective means to promote the cooperative e-commerce. In order to guide cooperative e-commerce, it should actively promote cooperatives to carry out brand certification. After adding the core independent variables, the difficulty of agricultural product sales and government sales support are still significant, both of which pass the $10 \%$ level of significance test, and the remaining control variables fail the $10 \%$ level of significance test.

\subsection{Robustness analysis}

Generally speaking, the cooperative e-commerce has certain requirements for the chairman's human capital, and receiving education is an important way to improve the chairman's human capital. The lower the education level, 
the chairman's human capital may not be enough to support the cooperative to participate in the e-commerce, and the cooperative has a lower probability of developing the e-commerce sales. The higher the education level, the more the chairman can realize the value of the cooperative e-commerce and have a certain amount of human capital to participate in the e-commerce. Therefore, in order to test the robustness of the results, this article eliminates the samples with the education less than 6 years and more than 16 years, and then re-regresses the core variables and control variables. The results are shown in table 4 , which is basically consistent with the results in table 3 . Brand certification has promoted the cooperative e-commerce, that is, the previous regression analysis results are more stable. Although the marginal impact of brand certification has changed, this change is not obvious.

Table4. Robustness analysis results

\begin{tabular}{|c|c|c|}
\hline Variables & Regression coefficient & Marginal coefficient \\
\hline$x_{1}$ & $1.136^{*}$ & $0.240^{* *}$ \\
\hline$x_{2}$ & 0.154 & 0.033 \\
\hline$x_{3}$ & 0.065 & 0.014 \\
\hline$x_{4}$ & 0.173 & 0.037 \\
\hline$x_{5}$ & 0.044 & 0.009 \\
\hline$x_{6}$ & -0.463 & $-0.098^{*}$ \\
\hline$x_{7}$ & $1.044^{*}$ & $0.220^{*}$ \\
\hline \multirow{2}{*}{ cons } & -0.87 & \\
\hline \multirow{2}{*}{$\begin{array}{c}\text { Related } \\
\text { inspection }\end{array}$} & Prob $>$ chi2 $=0.037$ & \\
\cline { 2 - 3 } & Log likelihood $=-57.976$ \\
\cline { 2 - 3 } & Pseudo $\mathrm{R} 2=0.114$ \\
\hline \multirow{2}{*}{ Note* * $\leq 0.1 * * * \mathrm{p} \leq 0.05 * * * \mathrm{p} \leq 0.01$} \\
\end{tabular}

\section{Conclusions and policy recommendations}

\subsection{Conclusion}

This article empirically analyzes the influence of brand certification on the cooperative e-commerce by binary logistic regression model based on the microscopic survey data of 100 vegetable cooperatives in Sichuan Province, and conducts a robust test on the results. The results show that the proportion of Sichuan vegetable cooperatives participating in the e-commerce is generally lower, which needs further improvement. Brand certification has a positive role in promoting cooperatives to participate in the e-commerce, with a marginal contribution of $19.7 \%$. In addition, government sales support has a positive impact on the cooperative e-commerce, which is an important guarantee for promoting cooperatives to participate in the e-commerce. While the difficulty of agricultural product sales has a negative impact on the cooperative e-commerce. The more difficult the agricultural products are sold, the higher the probability that the cooperative will participate in the e-commerce.

\subsection{Policy recommendations}

Based on the above research conclusions, this article makes the following policy recommendations:

(a) Promoting cooperatives to carry out brand certification. Guide the cooperatives' chairman to fully understand the role of brand certification in the promotion of the cooperative e-commerce, and then take brand certification as an important means to promote the cooperative e-commerce. On the one hand, cooperatives can register their own brands or use regional public brands, on the other hand, cooperatives should enhance the brand value of agricultural products in many ways, further indepth promoting the cooperative e-commerce.

(b) Promoting the cooperative e-commerce according to local conditions. Cooperatives are supposed to coordinate both offline and online marketing channels, and innovate the cooperative e-commerce model according to local conditions. Especially, focus on areas where agricultural product sales are difficult, cooperatives should use e-commerce to open agricultural product sales channels, which can also promote the sustainable development of themselves at the same time.

(c) Strengthening government sales support. Cooperative e-commerce is inseparable from the strong support of the government. The government should provide strong support in road transportation, cold chain logistics and marketing promotion, etc, which consolidates the external guarantee of the cooperative ecommerce.

\section{Acknowledgments}

First of all, I am very grateful to the tutor for the valuable suggestions on the article design, writing and modification; secondly, to my classmates and friends for helping me with the questionnaire survey.

Fund projects: (a) Soft Science Project from the Ministry of Agriculture and Rural Affairs (201903), (b) Key Planning Project from Sichuan Province Social Science Federation (SC19A009).

\section{Reference}

1. J. K. Huang, H. S. Deng, Z. G. Xu. The service function and its influencing factors of Chinese farmers' professional cooperative economic organizations [J]. Management World, 2010 (05): 7581.

2. X. S. Zhang. An analysis of the development trend of farmer professional cooperatives [J]. Management World, 2009 (05): 89-96.

3. D. R. Yang. Reason analysis and strategy empirical analysis on the "difficulty in agricultural products selling" of farmers' professional cooperatives [J]. Agricultural Economy, 2013 (10): 116-118.

4. Z. H. Huang, J. Zhang, K. Chen. Transaction costs and contract selection of farmers-Empirical evidence from the investigation of pear farmers in 30 villages in 15 counties in Zhejiang and Hebei 
provinces[J]. Management World, 2008 (09): 76-81.

5. J. Yang, H. J. Wang. Analysis of the transaction costs of agricultural products circulation-Theoretical comparison based on e-commerce and non-ecommerce [J]. Rural South, 2014,30 (08): 41-45.

6. T. Q. Zhao. Promote the construction of informatization and improve the development level of farmers' professional cooperatives [J]. China Farmers' Cooperative, 2011 (12): 34-37.

7. X. Z. Kong. Put the wings of e-commerce on the cooperative [J]. China Farmers Cooperative, 2015 (07): 33.

8. M. Qian, Z. H. Li, W. Wang. Comparison and applicability analysis of the "production-sales docking" and "production-consumption docking" models - Based on the investigation of cooperative agricultural product circulation paths [J]. Management Modernization, 2013 (05) : 47-49.

9. N. Zhang, L. Wang, C. Q. Li, et al. Research on the ecommerce model of farmers' professional cooperatives under the background of "Internet + " $[\mathrm{J}]$. E-commerce, 2017 (02): 28-30.

10. D. S. Chen, D. M. Qiu, H. D. Guo, et al. Comparative analysis of cooperatives' e-commerce model development [J]. China Farmers Cooperative, 2015 (07): 25-26.

11. L. Xu, Z. C. Si. Analysis of the Agricultural Products E-commerce Model of Farmer Cooperatives [J]. Jiangsu Rural Economy, 2016 (04): 65-66.

12. Y. Chen . Some thoughts on the marketing of farmer cooperatives in the Internet age [J]. China Farmer Cooperatives, 2014 (10): 52-54.

13. R. D. Zhang. Internet + agriculture: new opportunities for cooperative development [J]. China Farmers Cooperative, 2015 (07): 27-29.

14. Z. J. Wu, J. J. Qiu. Challenges, significance and mechanism of agricultural cooperatives operating fresh e-commerce platforms [J]. Science and Technology Management Research, 2015,35 (19): 197-201.

15. Z. Yao. Empirical study on the differences of ecommerce cognitive behaviors and influencing factors of new agricultural management entities [J]. China Circulation Economy, 2017, 31 (09): 46-52.

16. Y. F. Zhang. E-commerce sales of fresh fruits, farmers' willingness to participate and cooperatives embedding-survey data from farmers in Yantai big cherry production area [J]. Journal of Nanjing Agricultural University (Social Science Edition), 2016, 16 (01) : 49-58.

17. C. C. Wang, C. P. Xia, Y. Cai, et al. The impact of social trust on farmers' cooperative participation in ecommerce management [J]. Journal of China Agricultural University, 2019,24 (03): 198-209.

18. B. Liu, Y. M. Ye, X. L. Kang, et al. Analysis of the choice of farmers' e-commerce entrepreneurial behavior and its influencing factors-Based on the data of 150 farmers' e-commerce entrepreneurs in
Jiangxi province $[\mathrm{J}]$. Journal of Agricultural and Forestry Economic Management, 2019, 18 (01 ): 3642.

19. J. L. Luo, C. X. Qiu, J. Li. Research on cooperative resource base and willingness to participate in ecommerce model_-Based on 118 farmer professional cooperatives in Zhejiang Province [J]. Chinese Agricultural Science Bulletin, 2017,33 (14): 158- 164 .

20. B. Liu, X. K. Lei, C. Y. Du, et al. Influencing factors of farmers cooperatives participating in agricultural product e-commerce behaviors-Taking Jiangxi Province as an example [J]. Jiangsu Agricultural Sciences, 2017,45 (14): 284-288.

21. A. C. Dorr. Economic Analysis of Certification in the Brazilian Fruit "Chain. Cuvillier Publisher, Gottingen. 2009.

22. X. D. Zhang. Research on the influence of the coupling of agricultural product brand and culture on online sales [J]. Frontier, 2020 (01): 48-56.

23. C. Bacon. Confronting the coffee crisis: Can fair trade, organic,and specialty coffees reduce small-scale farmer vulnerability in Northern Nicaragua? World Develop [J]. 2005,33(3), 497-511.

24. P. R. Jena, B. B. Chichaibelu, T. Stellmacher, et al. The impact of coffee certification on small-scale producers' livelihoods: a case study from the Jimma Zone, Ethiopia[J]. Agricultural Economics, 2012, 43(4): 429-440.

25. R. X. Wang. The conditions and feasibility for farmers' cooperatives to engage in e-commerce [J]. China Farmers' Cooperative, 2016 (06): 41-42.

26. Y. Y. Dong, Y. Zhu. Discussion on the development of agricultural product e-commerce by farmers professional cooperatives [J]. Zhejiang Agricultural Sciences, 2012 (02): 262-265. 